\title{
Sexuality and Quality of Life in Eastern Taiwan People With Schizophrenia
}

\author{
Mei Hua Chung \\ National Pingtung University of Science \& Technology \\ Jian Kang Chao ( $\square$ jiankangchao2000@yahoo.com.tw ) \\ Taipei Veterans General Hospital \\ Mi Chia Ma \\ National Cheng Kung University \\ Ru Wei Lin \\ National Pingtung University of Science \& Technology
}

\section{Research Article}

Keywords: people with schizophrenia, sexual desire, depression, quality of life, brief psychiatric rating scale

Posted Date: July 23rd, 2021

DOI: https://doi.org/10.21203/rs.3.rs-514841/v1

License: (c) (i) This work is licensed under a Creative Commons Attribution 4.0 International License. Read Full License 


\section{Abstract}

Background: A proper sexual functioning and a satisfying intimate relationship is one of the components for a high quality of life (QoL). However, sexuality among the chronically and/or those who suffer from mental illnesses are not a widely researched or discussed topic. The aim of the study is to explore the association among brief psychiatric rating scale (BPRS), QoL, Taiwanese depression questionnaire (TDQ), sexual desire (SD) in people with schizophrenia (PwS).

Methods: This study used a cross-sectional design with 277 psychiatric inpatients. A descriptive analysis, difference analysis and logistic regression model were presented to identify relevant variables that may affect the probability of good QoL. Finally, we used structure equation model to explore the association of BPRS, TDQ, SD and QoL.

Results: The mean age of the sample was $43.82 \pm 8.43$ years old. Quality of life has no significant difference in the obesity and gender of PwS, but male PwS had higher scores of SD than female PwS. For participants with smoking, early illness onset age, shorter illness duration there was a significant higher SD. The logistic regression analysis showed BPRS, depression and SD significantly affected the probability of QoL. By SEM, SD would be positivity correlated with mental status and that SD would indirectly influence QoL.

Conclusions: Our results showed that the QoL and SD of the PwS are often associated with interaction between psychological and sociological factors. This study also supports the idea of a close relationship between SD, depression and BPRS. Besides, these factors may predict the probability of good life quality for the PwS.

\section{Background}

Sexual life is a natural component of human behavior, PwS often have their sexual rights ignored and this can become a problem. The various components of sexual functioning - libido, arousal, ejaculation, and orgasm - can all be impaired by schizophrenia in the psychological and pathophysiological aspects [1]. Schizophrenics can suffer from many sexual problems, such as erectile dysfunction, decreased libido or disturbances in ejaculation/orgasm [2], these could be a result of the disease or the medications they are taking. Sexual problems in PwS may be related to their symptoms, decreased initiative, and motivation due to their disease status; these problems are also induced by psychosocial factors, somatic health and the use of psychotropic medications $[3,4]$.

In the last two decades, there has been increasing interest in QoL among PwS, as they have a severe, disabling, lifelong disorder, associated with severe social and occupational dysfunction. PwS can take medication that may induce erectile dysfunction, decreased libido or disturbances in ejaculation/orgasm [5]. Olfson's study showed that schizophrenic patients with current sexual dysfunction showed significantly poorer global QoL and less satisfaction enjoyment in their lives when compared to patients without current sexual dysfunction [6]. Ma's study also points out quality of sexual life and sexual dysfunction on PwS are associated with interactions among psychological, sociological, and biochemical-pharmacological factors [7]. 
Sexual functioning has received little attention or recognition as an important aspect of care; However, sexuality in chronic and/or severe mental illness is not a widely researched or widely discussed topic. The main aims of our study are to assess the association among SDI, TDQ, BPRS and QoL in a sample of PwS, whom were admitted to a chronic in-patient care unit.

\section{Methods}

\section{Materials and methods}

The used data comes from a cross-sectional survey on demographic items, SDI, BPRS, QoL, and TDQ among patient of chronic psychiatric hospital institute in eastern Taiwan carried out in 2019. The hospital (Yuli branch, Taipei Veterans General Hospital) offers a pleasant environment. In operating as a community, it differs from other psychiatric hospital in Taiwan. Besides the main campus, there are also day care services, recovery home, nursing home, and community home. By uniting specialties in nursing, community work, clinical psychology, and occupational therapy staff improve patient's mental health. People with schizophrenia who joined live in the community, they function like normal member of the community and operates as part of the community, so they can live in the city like normal people, who can shop, visiting friends and running night market shops. They have normal social relationship, even opportunities for sexual relationships in Yuli town. A total of 300 participants were evaluated from chronic psychiatric hospital institute, with 277 (response rate $=92.3 \%$ ) completed questionnaires being returned.

Data was from 277 patients living in psychiatric hospital institute in eastern of Taiwan. The Ethics Committee of Science and Technology which includes the Institutional Review Board (IRB) of Chang Gung University has approved the proposal and was in accordance with the Declaration of Helsinki. All participants provided informed written consent.

The study was a cross-sectional design and purposive sampling was used. The participants were not limited to specific departments, but had to be over 20 years old. Eligible individuals were: (a) clinically stable inpatients in the chronic psychiatric hospital institute in eastern Taiwan; (b) diagnosed with schizophrenia according to the criteria of the Diagnostic and Statistical Manual of Mental Disorders (DSM-IV, American Psychiatric Association, 1994) [8] assessed by administering the Structured Clinical Interview of DSM-IV [9];

(c) had been ill for a minimum of 5 years; (d) were 20 to 65 years of age; (e) had received at least 6 weeks of treatment with an antipsychotic; and (f) provided informed consent to participate in the study. Exclusion criteria included: (a) gonadal injury; (b) They had a general medical condition or history of a surgical procedure known to cause sexual dysfunction; (c) Uncontrolled psychiatric symptoms, diabetes mellitus, history of stroke, congestive heart failure, unstable cardiac condition, arrhythmia, or myocardial infarction within the last 6 months; (d) substance abuse; (e) inability to give informed consent or answer questions.

\section{Procedure}

Self-reported questionnaire was used for data collection. There was a cover letter on the questionnaire describing the purpose of the study and stressing the confidentiality of the given information. The BPRS score was assessed by two independent experienced psychiatrists. They received a short training session 
for BPRS, that are relatively accurate when compared to "gold standard" ratings established for assessment of people with schizophrenia.

The IRB consent form was signed by the participants before they started to fill out the questionnaire. The participants were asked to indicate their height, weight, BMI (body mass index), demographic data, QoL, SDI in the questionnaire. The participants were placed in a quiet room to complete the anonymous selfadministered survey.

\section{Assessment instruments}

Demographic questionnaire

There were 16 demographic items, including gender, age, relationship condition, educational category, religion, smoking and drinking habits, awareness of one's health condition, relation to a partner, and so forth. Data was gathered using self-reported questionnaires and in-person interviews. BMI is a statistical measurement defined as the body weight (in kilograms) divided by the square of the height (in meters). The Taiwanese Department of Health defines overweight as a person's BMI is greater than 24 and obese as one's $\mathrm{BMI}$ is greater than 27. These definitions differ from those of WHO-Asia, which defines overweight as a person's BMI greater than 23 and obese as one's BMI greater than 25 [10]. The Taiwanese obesity definition was used in this study.

Sexual Desire Inventory (SDI)

The Chinese version of SDI (SDI-C) was based on Spector's 14-item SDI, each item is rated 0-8 [11], and it was used to measure SDI in this study. Based on the factor analysis results of Lee et al., the 14-item scale was categorized into 3 items, namely solitary, dyadic, and mixed items. The fit indices were $p=0.68$ and GFI $=0.93$ for the 3 -item model [12].

Brief Psychiatric Rating Scale (BPRS)

The brief psychiatric symptom evaluation form is used in assessing the changes before and after treatment in patients with schizophrenic symptoms, the total score is higher if unusual behavior is more serious. Each symptom is rated $0-4$ and a total of 18 symptoms are scored. The oldest foreign scale was first published in 1962 [13]. The domestic scholars obtained licensing rights for translations into Chinese, slightly modified to comply with the actual conditions of Taiwanese [14].

Quality of Life (QoL)

The brief version of the World Health Organization QoL (WHO-QoL-BREF) questionnaire (Taiwan edition) is an abbreviated version of the 100-item WHO-QoL questionnaire. WHO-QoL-BREF is to assess an individual's perception in the context of their culture and value system, personal goals, standards, and concerns [15]. The Taiwan edition of WHO-QoL-BREF contains 28 five-point items, each item is rated $0-4$. Higher WHOQoL-BREF scores represent higher perceived QoL.

Taiwanese Depression Questionnaire (TDQ) 
The TDQ which was a 4-point scale with 18 items is a culturally specific depression self-rating instrument for effective screening of depression symptoms in Taiwan. It had a sensitivity of 0.89 and a specificity of 0.92 at a cutoff score of 19 , and had satisfactory reliability and validity (Cronbach's alpha coefficient of 0.90 , and the area under the ROC curves of 0.92) [16].

\section{Statistical Analysis}

SPSS Version 17.0 statistical software was used in this study to perform descriptive analysis and difference analysis. Because the data of age, educational level, QoL, depression and SDI were not normal distribution, hence, the comparison of means under each categorized demographic variable (e.g., gender, BMI, illness onset age and illness duration) were examined with the Mann-Whitney $\mathrm{U}(\mathrm{M}-\mathrm{W} \mathrm{U})$ test or the Kruskal-Wallis $\mathrm{H}$ test (K-W H test). To evaluate the QoL affected by BPRS, depression and SDI, we used the multiple logistic regression analysis to find the effect of all variables on the probability of good life quality for the PwS. Besides, we used structure equation model (SEM) to explore the association of BPRS, TDQ, SDI and QoL. Data analyses were conducted with SPSS for Windows version 17 (SPSS, Chicago Illinois, USA) and Amos. The difference among groups was considered significant if the $p$-value was less than 0.05 .

\section{Results}

Two hundred and seventy-seven PwS were available for analysis. The mean \pm sd for age of all study participants was $43.82 \pm 8.43$. The mean \pm sd for education was $10.97 \pm 3.00$ years, for BPRS was $9.53 \pm$ 6.66, for QoL was 60.27 \pm 15.57 , for TDQ score was $9.86 \pm 10.06$, for SDI was $27.24 \pm 24.70$.

We used the non-parametric M-W U test to analyze the relationship between age, educational level, QoL, depression, SDI and its items and gender. Table 1 showed that there was significant relation between age, BPRS, SDI in total scale, solitary, dyadic, comparative items and gender. Male participants were younger than female participants $(p=0.014)$, male participants had higher BPRS $(p=0.019)$ and higher SDI and its items $(p<0.001)$. Table 2 showed that there was significant relation between SDI, solitary, dyadic, comparative items with the combination of obesity and gender in $\mathrm{K}-\mathrm{W} \mathrm{H}$ test. 
Table 1

The comparison of quality of life, depression and sexual desire by gender

\begin{tabular}{|llll|}
\hline variable & $\begin{array}{l}\text { female } \\
(\mathbf{n}=\mathbf{8 3})\end{array}$ & $\begin{array}{l}\text { male } \\
(\mathbf{n}=194)\end{array}$ & P value \\
\hline Age & $45.49 \pm 7.28$ & $43.11 \pm 8.80$ & $0.014^{\star}$ \\
\hline Education level & $11.07 \pm 3.29$ & $10.93 \pm 2.88$ & 0.871 \\
\hline BPRS & $8.35 \pm 6.86$ & $10.04 \pm 6.53$ & $0.019^{*}$ \\
\hline BMI & $25.65 \pm 3.98$ & $24.88 \pm 3.98$ & 0.252 \\
\hline Quality of life & $59.40 \pm 15.96$ & $60.64 \pm 15.43$ & 0.461 \\
\hline Depression & $10.04 \pm 9.78$ & $9.36 \pm 10.37$ & 0.572 \\
\hline Sexual desire total & $14.31 \pm 17.71$ & $32.77 \pm 25.23$ & $<0.001^{\star}$ \\
\hline Solitary & $3.94 \pm 6.03$ & $9.18 \pm 8.17$ & $<0.001^{\star}$ \\
\hline Dyadic & $7.37 \pm 9.98$ & $16.01 \pm 13.76$ & $<0.001^{\star}$ \\
\hline Comparative & $2.83 \pm 3.62$ & $7.53 \pm 5.70$ & $<0.001^{\star}$ \\
\hline Using Mann-Whitney U test & & \\
\hline * Significantly different $(p-v a l u e<0.05)$ & \\
\hline BPRS: Brief Psychiatric Rating Scale; BMl: Body Mass Index \\
\hline
\end{tabular}


Table 2

The comparison of quality of life, depression and sexual desire by the combination of gender and BMI

\begin{tabular}{|llllll|}
\hline & female BMI <27 & $\begin{array}{l}\text { female } \\
\text { BMI } 27\end{array}$ & $\begin{array}{l}\text { male } \\
\text { BMI }<27\end{array}$ & $\begin{array}{l}\text { male } \\
\text { BMI } 27\end{array}$ & \\
\hline variable & $(n=55)$ & $(n=28)$ & $(n=137)$ & $(n=57)$ & P value \\
\hline Age & $45.60 \pm 7.30$ & $45.29 \pm 7.35$ & $43.71 \pm 8.81$ & $41.67 \pm 8.68$ & 0.133 \\
\hline Education level & $11.44 \pm 3.08$ & $10.36 \pm 3.62$ & $10.95 \pm 2.82$ & $10.89 \pm 3.05$ & 0.197 \\
\hline BPRS & $8.24 \pm 7.28$ & $8.57 \pm 6.08$ & $9.72 \pm 6.57$ & $10.82 \pm 6.41$ & 0.072 \\
\hline Quality of life & $59.31 \pm 16.87$ & $59.57 \pm 14.28$ & $61.94 \pm 16.31$ & $57.53 \pm 12.66$ & 0.130 \\
\hline Depression & $9.62 \pm 9.38$ & $10.86 \pm 9.45$ & $8.78 \pm 9.34$ & $12.19 \pm 12.27$ & 0.303 \\
\hline Sexual desire total & $12.49 \pm 16.58$ & $17.89 \pm 19.58$ & $31.30 \pm 25.71$ & $36.30 \pm 23.89$ & $<0.001^{*}$ \\
\hline Solitary & $3.47 \pm 5.90$ & $4.86 \pm 6.46$ & $8.69 \pm 8.13$ & $10.35 \pm 8.30$ & $<0.001^{*}$ \\
\hline Dyadic & $6.49 \pm 9.15$ & $9.11 \pm 11.43$ & $15.15 \pm 13.93$ & $18.07 \pm 13.23$ & $<0.001^{*}$ \\
\hline Comparative & $2.44 \pm 3.46$ & $3.61 \pm 3.86$ & $7.42 \pm 5.91$ & $7.81 \pm 5.22$ & $<0.001^{*}$ \\
\hline Using Kruskal-Wallis H test & & & & \\
\hline * Significantly different $(p$-value $<0.05)$ & & & & \\
\hline BPRS: Brief Psychiatric Rating Scale & & & & \\
\hline
\end{tabular}

In this study, we divided participants with schizophrenia to three groups of below 20 years old, 20-29 years old, and not less than 30 years old in the onset age of mental illness. Then we used K-W H test to compare the means of educational level (or BPRS, QoL, depression and SDI) for three groups of illness onset age. Table 3 showed that participants with schizophrenia illness and late onset age had a significantly higher QoL scores $(p=0.03)$, lower depression score $(p=0.012)$. 
Table 3

The comparison of quality of life, depression and sexual desire by illness onset age

\begin{tabular}{|c|c|c|c|c|}
\hline & $\begin{array}{l}<20 y / 0 \\
(n=85)\end{array}$ & $\begin{array}{l}20-29 y / 0 \\
(n=145)\end{array}$ & $\begin{array}{l}\geq 30 y / 0 \\
(n=47)\end{array}$ & p-value \\
\hline Age & $39.62 \pm 8.17$ & $44.24 \pm 7.68$ & $50.13 \pm 6.82$ & $<0.001^{*}$ \\
\hline Education level & $10.91 \pm 2.80$ & $10.89 \pm 3.06$ & $11.36 \pm 3.21$ & 0.549 \\
\hline BPRS & $10.25 \pm 6.57$ & $9.50 \pm 6.85$ & $8.36 \pm 6.19$ & 0.271 \\
\hline Quality of life & $57.52 \pm 15.30$ & $60.53 \pm 15.29$ & $64.45 \pm 16.22$ & $0.030 *$ \\
\hline Depression & $11.88 \pm 10.13$ & $9.39 \pm 10.11$ & $7.64 \pm 9.33$ & $0.012^{\star}$ \\
\hline Sexual desire total & $27.95 \pm 25.18$ & $28.60 \pm 25.67$ & $21.74 \pm 20.03$ & 0.368 \\
\hline Solitary & $7.65 \pm 8.12$ & $8.12 \pm 8.29$ & $5.94 \pm 6.61$ & 0.418 \\
\hline Dyadic & $14.00 \pm 14.09$ & $14.05 \pm 13.68$ & $10.43 \pm 10.33$ & 0.473 \\
\hline Comparative & $6.20 \pm 5.83$ & $6.34 \pm 5.74$ & $5.32 \pm 4.65$ & 0.726 \\
\hline \multicolumn{5}{|c|}{ Using Kruskal-Wallis $\mathrm{H}$ test } \\
\hline \multicolumn{5}{|c|}{ *Significantly different $(p$-value $<0.05)$} \\
\hline BPRS: Brief Psych & c Rating Scale & & & \\
\hline
\end{tabular}

Similarly, K-W H test was performed in four groups of less than 10 years, 10-19 years, 20-29 years, and $\geqq$ 30 years in the illness duration. Table 4 showed that there were significant relationships between illness duration and SDI total score $(p=0.005)$, dyadic item $(p=0.002)$, comparative item $(p=0.008)$. There was no significant difference between the four groups in the educational level, BPRS, QoL, depression score and SDI (solitary item). 
Table 4

The comparison of quality of life, depression and sexual desire by illness duration

\begin{tabular}{|c|c|c|c|c|c|}
\hline & $\begin{array}{l}<10 \text { years }(\mathrm{n}= \\
27)\end{array}$ & $\begin{array}{l}10-19 \text { years }(n= \\
90)\end{array}$ & $\begin{array}{l}20-29 \text { years }(n= \\
119)\end{array}$ & $\begin{array}{l}\geq 30 \text { years }(n= \\
41)\end{array}$ & $\begin{array}{l}\mathrm{p}- \\
\text { value }\end{array}$ \\
\hline $\begin{array}{l}\text { Education } \\
\text { level }\end{array}$ & $11.44 \pm 2.98$ & $10.64 \pm 2.87$ & $10.97 \pm 2.96$ & $11.39 \pm 3.43$ & 0.450 \\
\hline BPRS & $7.41 \pm 6.63$ & $10.46 \pm 6.43$ & $9.55 \pm 6.83$ & $8.88 \pm 6.52$ & 0.100 \\
\hline $\begin{array}{l}\text { Quality of } \\
\text { life }\end{array}$ & $60.00 \pm 17.29$ & $57.99 \pm 15.72$ & $61.87 \pm 14.91$ & $58.20 \pm 15.48$ & 0.249 \\
\hline Depression & $7.30 \pm 8.75$ & $11.53 \pm 11.518$ & $9.32 \pm 9.37$ & $9.44 \pm 9.12$ & 0.253 \\
\hline $\begin{array}{l}\text { Sexual } \\
\text { desire }\end{array}$ & $31.00 \pm 22.76$ & $33.76 \pm 25.87$ & $22.37 \pm 22.82$ & $24.59 \pm 25.77$ & $0.005^{\star}$ \\
\hline Solitary & $8.00 \pm 7.57$ & $9.24 \pm 8.82$ & $6.66 \pm 7.30$ & $6.51 \pm 7.89$ & 0.091 \\
\hline Dyadic & $16.15 \pm 12.40$ & $16.90 \pm 14.13$ & $10.52 \pm 11.98$ & $12.39 \pm 14.17$ & $0.002^{\star}$ \\
\hline Comparative & $7.62 \pm 6.36$ & $7.62 \pm 5.96$ & $5.66 \pm 5.45$ & $5.18 \pm 5.78$ & $0.008 *$ \\
\hline \multicolumn{6}{|c|}{ Using Kruskal-Wallis $\mathrm{H}$ test } \\
\hline \multicolumn{6}{|c|}{ *Significantly different $(p$-value $<0.05)$} \\
\hline \multicolumn{6}{|c|}{ BPRS: Brief Psychiatric Rating Scale } \\
\hline
\end{tabular}

The results of multiple logistic regression analysis indicated significant ORs for $\mathrm{BPRS}(\mathrm{OR}=0.918,95 \% \mathrm{Cl}=$ $0.878-0.960, p<0.001)$, depression ( $\mathrm{OR}=0.952,95 \% \mathrm{Cl}=0.923-0.982, p=0.002), \mathrm{SDI}(\mathrm{OR}=1.013,95 \% \mathrm{Cl}=$ $1.002-1.024, p=0.018)$, respectively. Depression and BPRS had negatively correlated on the probability of good QoL. Sexual desire had positively correlated on the probability of good QoL (Table 5).

Table 5

The related variables affect the probability of good life quality by the multiple logistic regression

\begin{tabular}{|c|c|c|c|c|c|c|}
\hline & coefficient & S.E. & p-value & OR & LCL & UCL \\
\hline constant & 0.813 & 0.262 & & & & \\
\hline BPRS & -0.086 & 0.023 & $<0.001^{*}$ & 0.918 & 0.878 & 0.960 \\
\hline Depression & -0.049 & 0.016 & $0.002^{\star}$ & 0.952 & 0.923 & 0.982 \\
\hline Sexual desire & 0.013 & 0.006 & $0.018^{\star}$ & 1.013 & 1.002 & 1.024 \\
\hline \multicolumn{7}{|c|}{ The reference group is total score of life quality $<59$. } \\
\hline \multicolumn{7}{|c|}{ *Significantly different $(p$-value $<0.05)$} \\
\hline BPRS: Brief P & chiatric Rati & Scale & & & & \\
\hline
\end{tabular}


Finally, we used structure equation model (SEM) to explore the association of BPRS, TDQ, SDI and QoL. BPRS was divided into five items: Anxiety, Inactive, Disorder, Activating and Hostile; TDQ was divided into three items: Thinking, Physiology and Psychology. SDI was divided into three items: Dyadic, Solitary and Comparative. QoL was divided into four items: environment, social relations, psychological level and physiological level.

In Fig. 1, the overall fit assessment indicator of the SEM model was $\chi^{2} / d f=1.671$ with a goodness-of-fit index of 0.937 , adjusted goodness of-fit index of 0.912 , and approximated root mean square error of 0.049 , which all reached the standards $\chi^{2} / d f<5$, goodness-of-fit index $\geq 0.9$, adjusted goodness-of-fit index $>0.9$, approximated root means square error $<0.05$ )

By Amos, the structural reliabilities of the four dimensions-namely, BPRS, depression, SD, and QoL-were $0.779,0.760,0.870$ and 0.858 , respectively, and the average extracted variances were $0.548,0.718,0.811$, and 0.720 . Structural reliabilities of all dimensions were more than 0.7 and extracted variances were also all greater than 0.5 . Hence, this model had a reliable fit for the internal structure. Figure 1 showed that $73 \%$ of BPRS can be interpreted by mental status, and $60 \%$ of depression can be interpreted by mental status. The influence of each dimension was explained as follows.

i. Influence of SD on mental status: Sexual desire has significant, proportional, and direct influence on mental status.

ii. Influence of SD on QoL: Sexual desire has no direct relation on QoL; however, via mental status, it has an indirect influence.

iii. Influence of mental status on QoL: Mental status has significant, inversely proportional, and direct influence on QoL.

The path coefficient estimates and $t$ values of standardized model are as follows: SD to mental status: 0.17 $(t=2.059, p<0.05)$, and mental status to QoL: $-0.53(t=-4.212, p<0.001)$. The overall model structure can be simplified as shown in Fig. 2.

The influences among variables can be grouped into direct effects, indirect effects, and overall effects. Overall effects which is the sum of the direct effects and indirect effects. Sexual desire has a direct effect of 0.17 to mental status and an indirect effect of 0 ; mental status has a direct effect of -0.53 to QoL and an indirect effect of 0; the SD has an indirect effect, with an indirect effect coefficient of -0.0901, which is found by multiplying the two direct effects $0.17 \times(-0.53)$. Hence, mental status has a bigger overall effect coefficient on QoL than that of SD.

\section{Discussion}

Sexual life is an important aspect in human functions, but physicians and psychiatrists often may fail to discuss with patients their sexual health, and sexual problems were under-estimated in psychotic patients. The illness itself can interfere with normal expression of sexuality though, sexual problems can result from a 
wide variety of psychological and physical causes, so treatments for PwS that aim to go beyond the narrow focus of reducing symptoms and, rather, focus on QoL issues will necessarily include consideration of patients' functioning and dysfunction into treatment planning and provision of care [2, 17].

Studies by Aizenberg [18], the PwS reported significant increases in SD reduction compared against unaffected controls, while SD was less frequent in patients using psychotropic medications as well as in those not using psychotropic medications. Derogatis's study results showed that the prevalence of sexual dysfunction among all women is estimated to be between $25 \%$ and $63 \%$, and is high relative to men [19]. In men, a high BPRS general psychopathology score was associated with an increased risk of sexual dysfunction. Studies have shown that a majority of untreated PwS have a reduced desire for sex, more in females as compared to males, in 2003 Macdonald's Nithsdale schizophrenia surveys results showed that patients with schizophrenia, $82 \%$ of males and $96 \%$ of females reported at least one sexual dysfunction [20]. Parish also point out low desire in women is an extremely common problem (37.7\%), and low desire that causes personal distress [21]. Some studies also found that sexuality of female PwS were more impaired. Ben Mahmoud's study showed that more decreased desire and arousal in women with schizophrenia [22, 23]. Our study results showed that women were fewer than men in the SDI among PwS; this result was similar to that of Ben's report. In this study it also showed that the female group older than the male group had a BPRS lower than male group (Table 1).

In male PwS their sexual activity if often limited to masturbation, due to negative symptoms that limit their ability to maintain relationships. Seeman's study also point out multiple factors influence sexual function in PwS, including the effects of psychiatric symptoms, age, depressive symptoms, institutionalization, and psychotropic medication [24]. Several proposed mechanisms for antipsychotic induced loss of libido exist like dopamine antagonism can induce to impairment of motivation and reward cycle and therefore decreased libido. Van Sant also point out elevated prolactin induced to antidopaminergic activity is associated with hyerprolactinemia and decreased libido [25]. In our study it showed no difference in QoL, BPRS, depression. But SD and its items were significant between the combination of gender and obese PwS (Table 2). Nackers's reports showed that women's overall BMI change across 13.8 years of follow up was not associated with overall changes in sexual functioning, SD [26]. Some studies had similar reports that women's sexual functioning and frequency of intercourse have not been associated with obesity, defined by a $B M I \geq 30 \mathrm{~kg} / \mathrm{m}[2,27,28]$.

Patients with schizophrenia may influence sexual behavior in men and women in different ways [29]. This may be related to the differences in the age of onset of schizophrenia. Women often develop schizophrenia later in their life, which may be due to the effects of sex hormones [30]. Immonen's systematic review and meta-analysis study showed that there is a statistically significant association between lower age of onset and frequent hospitalizations, negative symptoms, frequent relapses, poorer social/occupational functioning and poorer global outcome [31]. Smith reports' also point out the prevalence of major depressive disorder for 18-29-year-olds is threefold higher than that of 60-year-olds, and the prevalence in women is 1.53-fold higher than men [32]. Our study had similar results and results showed that early onset PwS had higher depressive symptoms score and lower QoL score (Table 3). 
Research showed that institutionalized patients, both males and females with chronic schizophrenia presented decreased interest in sexual activity, decreased frequency of intercourse, and decrease in satisfaction from sexual interactions [33]. Psychiatric symptoms, institutionalization, and psychotropic medication contribute to frequently occurring impairments in sexual functioning and QoL. Some studied results also showed that PwS are chronic and relapsing, and have been correlated with impaired cognitive function as well as interpersonal skills. These disorders also affect the sexual function and social function in patients [34,35]. In a study by Kandrakonda [36] show that sexual dysfunction is very common in patients receiving long-term treatment with antipsychotics, and it is associated with a great impact in a substantial proportion of patients. Our study showed results that long-term illness duration (over 20 years) patients had lower SD total scores, dyadic items and similar items than short-term illness duration (less than 20 years) patients. Patients with schizophrenia for over twenty years had longer institutionalization and longer-term use of psychotropic medication, which contribute to recurring impairments in SD (Table 4).

Low or decreased SD can cause personal distress. Some studies report that severity of illness was found to be negatively correlated with overall QoL $[37,38]$, the mental illness itself can interfere with normal expression of sexuality thought. Psychiatric symptoms, institutionalization, depression and psychotropic medication contribute to frequently occurring impairments in sexual functioning and QoL. In our study it also showed that the QoL had strong correlation with BPRS, depression and SD.

\section{Limitations}

In this study we did not make an initial assessment of participants' sexual dysfunction before treatment, and the participants were free to take any medications including any antipsychotic agents during the study. Therefore, the side effects the participants experienced might have been influenced by the medications they were taking; this requires us to be cautious in our interpretations. Second, the data may be biased, as the questionnaire was self-reported, with $7.7 \%$ of participates not responding to the survey. However, an attempt was made to minimize this bias by ensuring privacy during the completion of the questionnaire and using the anonymous self-administered survey. And third, a bias introduced by under-reporting is possible as sexual problems is a sensitive issue and may be considered socially unacceptable in mainly Chinese cultural settings [39].

\section{Conclusion}

Sexuality is a key function of human beings, sexuality, sexual relationships and sexual functioning are all important QoL issues for PwS. Quality of life has been recognized as an important outcome of schizophrenia treatment. This study confirms the strong association of QoL with severity of psychiatric symptoms, depression and SD. Clinicians often do not ask and underestimate the rates of sexual problems, as well as their negative impact on the lives of the PwS. Some clinicians may have limited knowledge of the issue [40]. Therefore, there is a need among clinicians for increased sexual health knowledge, awareness and recognition of the sexual side effects of psychotropic medications on patients, especially those who are socially disadvantaged. Psychiatrists also should take depressive and sexual histories as a routine practice when prescribing psychotropic drugs and prominent psychopathological distresses. 


\section{Abbreviations}

QoL: Quality of Life; BPRS: The Brief Psychotic Rating Scale; TDQ: Taiwanese Depression Questionnaire; SD: Sexual Desire; SDI: Sexual Desire Inventory; PwS: people with schizophrenia; BMI: Body Mass index; IRB: Institutional Review Board; DSM-IV: Statistical Manual of Mental Disorders; M-W U: Mann-Whitney U test; KW H: Kruskal-Wallis H test; SEM: Structure Equation Model

\section{Declarations}

\section{Acknowledgments}

The authors thank all the clinicians for their contribution to this study.

\section{Authors' contributions}

MHC, MCM and JKC involved in the conception and design of the study, developed data collection tools, supervised data collection and analyzed data. JKC involved in manuscript writing. MHC, MCM and RWL helped with the manuscript preparation. All authors read and approved the final manuscript.

\section{Funding}

This study did not receive any fund.

\section{Availability of data and materials}

The datasets used during the current study are available from the corresponding author on reasonable request.

\section{Ethics approval and consent to participate}

The Ethics Committee of Science and Technology which includes the Institutional Review Board (IRB) of Chang Gung University has approved the proposal and was in accordance with the Declaration of Helsinki. All participants provided informed written consent.

\section{Consent for publication}

Not applicable.

\section{Competing interests}

The authors declare no competing interests.

\section{References}

1. Baggaley M. Sexual dysfunction in schizophrenia: focus on recent evidence. Hum Psychopharmacol 2008;23:201-9. doi: http://dx.doi.org/10.1002/hup.924 
2. Bushong ME, Nakonezny PA, Byerly MJ. Subjective quality of life and sexual dysfunction in outpatients with schizophrenia or schizoaffective disorder. J Sex Marital Ther 2013;39:336-46. [PubMed]

3. Marques TR, Smith S, Bonaccorso S, Gaughran F, Kolliakou A, Dazzan P, et al. Sexual dysfunction in people with prodromal or first-episode psychosis. Br J Psychiatry 2012;201:131-6.

4. Malik P, Kemmler G, Hummer M, Riecher-Roessler A, Kahn R, Fleischhacker WW, et al. Sexual dysfunction in first-episode schizophrenia patients: Results from European first episode schizophrenia trial. J Clin Psychopharmacol 2011;31:274-80.

5. Bobes J, Garcia-Portilla MP. Quality of life in schizophrenia. In: Katschnig H, Freeman H, Sartorius N, eds. Quality of Life in Mental Disorders.Chichester, UK: John Wiley \& Sons Ltd; 2005:153-68.

6. Olfson M, Uttaro T, Carson WH, Tafesse E. Male sexual dysfunction and quality of life in schizophrenia. J Clin Psychiatry2005;66:331-38. [PubMed]

7. Ma MC, Chao JK, Hung JY, Sung SC, Chao IHC. Sexual Activity, Sexual Dysfunction, and Sexual Life Quality Among Psychiatric Hospital Inpatients With Schizophrenia. J Sex Med 2018;15:324-33.

8. American Psychiatric Association. Diagnostic and Statistical Manual of Mental Disorders (DSM-IV), 4th ed, Text Revision. Washington, DC: American Psychiatric Press; 2000.

9. First MB, Spitzer RL, Gibbon M, Williams JB. Structured clinical interview for DSM-IV Axis I disorders, clinician version (SCID-CV). Washington, DC: American Psychiatric Press Inc; 1996.

10. Chu, NF. Prevalence of obesity in Taiwan. Obes Rev 2005;6:271-4.

11. Spector IP, Carey MP, Steinberg L. The Sexual Desire Inventory: development, factor structure, and evidence of reliability. J Sex Marital Ther 1996;22:175-90.

12. Lee HH, Chu YH, Ruan FF, Tzeng DS, Lung FW. Confirmatory factor analysis of the sexual desire inventory in patient with schizophrenia. Taiwanese J Psychiatry 2007;21:176-84.

13. Overall JE, Gorham DR. The brief psychiatric rating scale. Psychol Rep 1962;10:799-812.

14. Phillips MR, Xiong W, Wang RW, Gao YH, Wang XQ, Zhang NP. Reliability and validity of the Chinese versions of the Scales for Assessment of Positive and Negative Symptoms. Acta Psychiatr Scand 1991;84(4):364-70.

15. Yao G, Chung CW, Yu CF, Wang JD. Development and verifi cation of validity and reliability of the WHOQOL-BREF Taiwan version. J Formos Med Assoc 2002; 101:342-51.

16. Lee Y, Yang MJ, Lai TJ, Chiu NM, Chau TT. Development of the Taiwanese Depression Questionnaire. Chang Gung Med J 2000;23:688-94.

17. Östman M, Björkman AC. Schizophrenia and relationships: the effect of mental illness on sexuality. Clin Schizophr Relat Psychoses 2013;7:20-4.

18. Aizenberg D, Zemishlany Z, Dorfman-Etrog P, Weizman A. Sexual dysfunction in male schizophrenic patients. J Clin Psychiatry 1995;56:137-41.

19. Derogatis LR, Burnett AL. The epidemiology of sexual dysfunctions. J Sex Med 2008;5:289-300.

20. Macdonald S, Halliday J, MacEwan T, Sharkey V, Farrington S, Wall S, et al. Nithsdale Schizophrenia Surveys 24: sexual dysfunction: case-control study. Br J Psychiatry 2003;182:50-6. 
21. Parish SJ, Hahn SR. Hypoactive Sexual Desire Disorder: A Review of Epidemiology, Biopsychology, Diagnosis, and Treatment. Sex Med Rev 2016;4:103-20.

22. Kockott G, Pfeiffer W. Sexual disorders in non acute psychiatric outpatients. Compr Psy 1996;37(1):5661.

23. Ben Mahmoud S, Zouari L, Dammak M. Évaluation de la sexualité d'une série de 61 sujets atteints de psychose chronique. Sexologies 2013;22:90-6.

24. Seeman MV. Loss of libido in a woman with schizophrenia. Am J Psychiatry 2013;170:471-5. Available from:

https://www.researchgate.net/publication/236599534_Loss_of_libido_in_a_woman_with_schizophrenia [accessed Sep 08 2018].

25. Van Sant SP, Ahmed AO, Buckley PF. Schizophrenia, Sexuality, and Recovery. JEMH 2012;7 Available from: https://www.jemh.ca/issues/v7/documents/JEMH_Vol7SchizophreniaSexualityandRecovery.pdf [accessed Sep 09 2018]

26. Nackers LM, Appelhans BM, Segawa E, Janssen I, Dugan SA, Kravitz HM. Associations between body mass index and sexual functioning in midlife women: The Study of Women's Health Across the Nation (SWAN). Menopause (New York, NY). 2015;22(11):1175-81. doi:10.1097/GME.0000000000000452.

27. Bajos N, Wellings K, Laborde C, Moreau C, Group CSF. Sexuality and obesity, a gender persepctive: results from French national random probability survey of sexual behaviours. BMJ. 2010;340:c2573. [PMC free article][PubMed]

28. Smith AM, Patrick K, Heywood W, Pitts MK, Richters J, Shelley JM, et al. Body mass index, sexual difficulties and sexual satisfaction among people in regular heterosexual relationships: a populationbased study. Intern Med J 2012;42:641-51. [PubMed]

29. Verhulst J, Schneidman B. Schizophrenia and sexual functioning. Hosp Community Psychiatry 1981;32:259-62.

30. Abel KM, Drake R, Goldstein JM. Sex differences in schizophrenia. Int Rev Psychiatry 2010;22:417-28.

31. Immonen J, Jääskeläinen E, Korpela H, Miettunen J. Age at onset and the outcomes of schizophrenia: A systematic review and meta-analysis. Early Intervention in Psychiatry 2017;11:453-60.

32. Smith K. Schizophrenia and Depression-Understanding The Symptoms, Risks, \& Treatment Considerations. Available from: https://www.psycom.net/schizophrenia-and-depression.[accessed Sep 09 2018].

33. Lyketsos GC, Sakka P, Maïlis A. The sexual adjustment of chronic schizophrenics: a preliminary study. Br J Psychiatry 1983;143:376-82.

34. Huang $\mathrm{YM}, \mathrm{Kao} \mathrm{CY}, \mathrm{Hsu} \mathrm{JH}, \mathrm{Yu} \mathrm{CH}$. Analyses of the quality of life among patients with schizophrenia. Taiwanese J Psychiatry (Taipei) 2011; 25:158-66.

35. Kurtz MM, Gerraty RT. A meta-analytic investigation of neurocognitive deficits in bipolar illness: profile and effects of clinical state. Neuropsychology 2009;23:551-62.

36. Kandrakonda S, Jally MR, Reddy SRK, Miryala G. Prevalence of sexual dysfunction in patients with mental illness receiving psychotropic medication. AP J Psychological Medicine 2014;15(2):235-9. 
37. Gaur V, Jagawat T, Gupta S, Khan PA, Souza MD, Sharan A. Quality of life in outpatient Schizophrenics: Correlation with illness severity and psychopathology, Delhi Psychiatry Journal 2015;18:(1)95-101.

38. Chino B, Nemoto T, Fujii C, Mizuno M. Subjective assessments of the quality of life, well-being and selfefficacy in patients with schizophrenia. Psychiatry Clin Neurosci 2009;63(4):521-8.

39. Gao E, Lou C, Liu Y. Assessment on accuracy of the data concerning first sexual behavior in Shanghai, China. Reproduction and Contraception 2003;10:421-35.

40. Dossenbach M, Hodge A, Anders M, Molnár B, Peciukaitiene D, Krupka-Matuszczyk I, et al. Prevalence of sexual dysfunction in patients with schizophrenia: international variation and underestimation. Int $J$ Neuropsychopharmacol 2005;8:195-201.

\section{Figures}

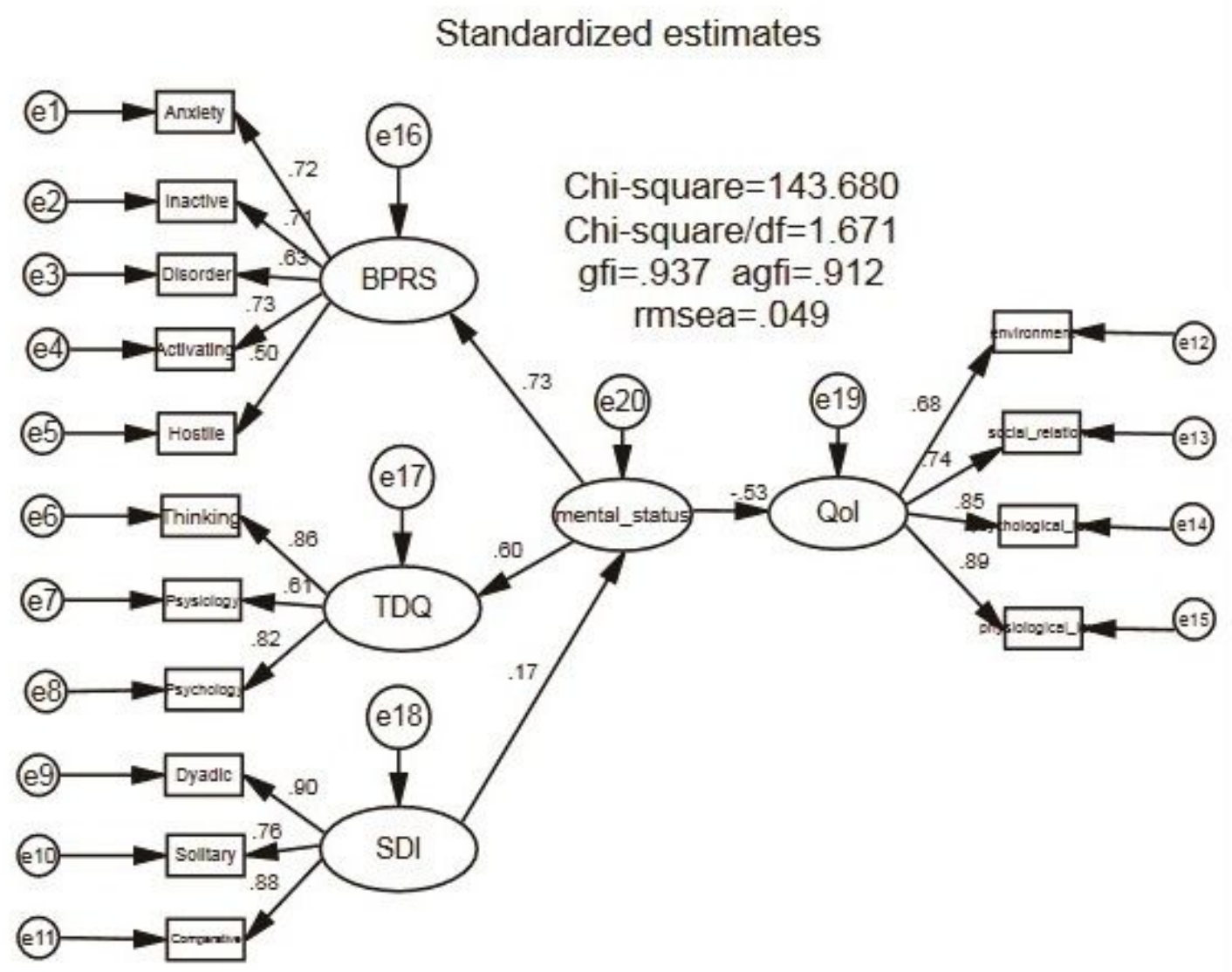

Figure 1

Standardized estimates 


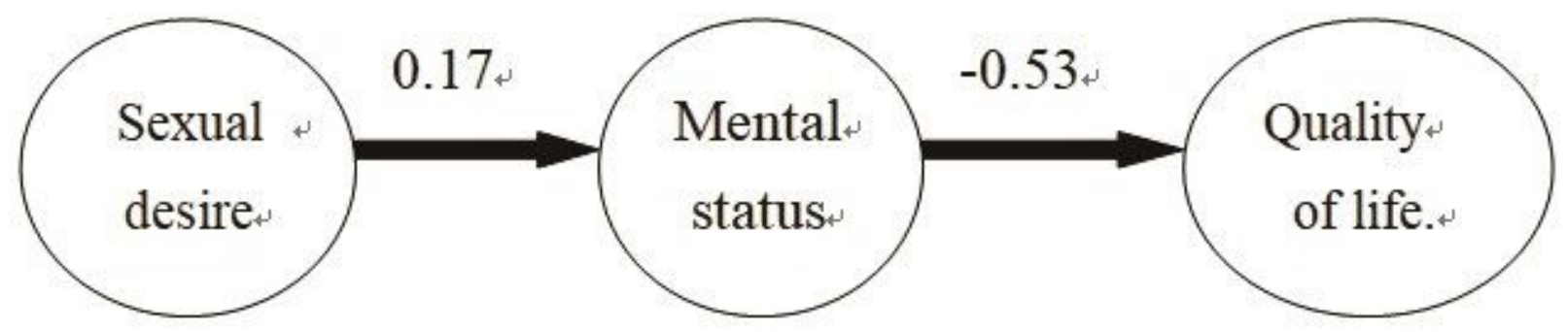

Figure 2

Structural diagram 